\title{
Research on the Differences between Traditional Decoration and Pre-fabricated Building Decoration
}

\author{
Hongbo Xia \\ Chongqing Real Estate College, Chongqing, China
}

Keywords: pre-fabricated building, integrated production, decoration; integrated decoration

\begin{abstract}
With numerous merits, pre-fabricated buildings have attracted the attention of our country and the architecture industry. In recent years, the new construction model develops rapidly since it is promoted vigorously. The decoration of pre-fabricated buildings is entirely different from the traditional decoration process in many aspects; these differences seriously hinder the improvement of pre-fabricated buildings' integration degrees. A thorough study on the differences between pre-fabricated building decoration and traditional decoration can help the decoration industry to transform and upgrade in the correct direction, theoretically support colleges and universities to reform curriculum and adjust personnel training programs, and build a sound platform to ensure the sustainable development of the architectural decoration industry.
\end{abstract}

\section{Introduction}

In recent years, pre-fabricated building has attracted widely attention due to its advantages like fast construction speed, low production cost, high engineering quality and less environmental pollution. In 2016, the State Council promulgated a series of policies and incentive mechanisms to vigorously promote the development of pre-fabricated buildings, and approved the guidance and development plans to promote and ensure the orderly development of pre-fabricated buildings at a national level. These measures aim to encourage more enterprises to engage in pre-fabricated building construction, and promote the adjustment and upgrading of the construction industry, so as to lay a good foundation for the development of fabricated buildings in China.

\section{Requirements of Prefabricated Buildings on Decoration}

The standardized components of pre-fabricated buildings are produced in factories in advance. On the construction site, workers only need to assemble and connect these components to complete the building. It is a reform in the form of housing construction, and will become the main way of building in the future. An ideal pre-fabricated building should be ready to welcome its guests once the assembly process is completed. Pre-fabricated buildings adopt high quality and standardized structural components and require accurate assembly. In order to keep the integrity of main structural components and ensure loading intensities, main components such as walls, columns and floors cannot experience the destructive secondary processing progress after construction. Meanwhile, in order to improve the overall assembly rates, shorten the construction duration and reduce construction pollution, assembly-type building and its supporting projects should be made up of components. The wet construction method should be avoided. Therefore, the traditional decoration process of installing decoration and other engineering equipment components after the construction of main structure cannot be adopted. When producing building components, decoration and related engineering components should be embedded and integrated in advance; they should be assembled with building components at the same time. Therefore, real pre-fabricated buildings require the integrated design, standardized component production and synchronized construction of civil, decoration, electrical, pipeline, installation and other engineering processes. Architecture and decoration technicians should cooperate with each other closely. At present, the integration levels of design, production and assembly of pre-fabricated buildings are far lower than the requirements in 
construction, decoration and other projects. These shortcomings seriously restrict the development of pre-fabricated buildings.

\section{The Current Relationship between Prefabricated Buildings and Architectural Decoration}

In China, the pre-fabricated building industry has laid certain foundation and accumulated technical experiences. Great achievements have been made in the integrated production and assembly of civil architectural components. But the development speed is relatively slow because of people's low acceptance levels and the immature technology of connecting buildings with other professional projects. The comprehensive integrated assembly level is still not high. As far as the relationship between pre-fabricated buildings and decoration is concerned, the integration of pre-fabricated buildings and decoration is mainly embodied in the integration of decoration and exterior walls. The components of exterior walls are closely integrated with decoration components, doors and windows. The integration level of interior decoration is very low, and mainly embodied in the integration of wall components and interior pipelines. Meanwhile, independent integrated kitchen cabinets, toilets and storage systems are also introduced. But interior walls, grounds, ceilings and other interfaces cannot be effectively integrated with structural components in design, production and assembly processes due to shortcomings related to integration technology, component transportation and connection technology. Therefore, the integration and assembly degrees of decoration and existing pre-fabricated buildings are still relatively low. Owners cannot move in when the building assembly is completed; they have to wait until traditional decoration projects are completed.

\section{Differences between Traditional Decoration and Pre-fabricated Building Decoration}

The concept of integration in pre-fabricated buildings requires a totally different decoration process from the traditional one. Pre-fabricated building decoration should have four major characteristics: standardized design, integrated production, assembly construction and information collaboration. Pre-fabricated architecture needs integrated components, and requires the synchronous design and assembly of architecture and decoration components. Civil structures of architecture include not only structural components, but also pipelines and decorative surfaces. The assembly of civil structural components should be carried out together with the assembly and connection of decoration components, electric circuits and pipelines. Diversified construction projects should be integrated into one assembly process. The decoration of external walls, doors, windows, internal walls, floors and ceilings should be completed at the same time with the assembly of main building components. Then integrated kitchens, bathrooms and storage cabinets can be installed.

As a result, the technology and process of pre-fabricated building decoration are totally different from those of the traditional decoration.

Traditional decoration process goes as following: civil structure construction - design and construction of external wall decoration - indoor decoration design - indoor main structure demolition - indoor concealed work construction - flooring - wall, column and ceiling construction - installation of doors and windows - installation of hardware sanitary fittings, electric equipments and furniture.

Pre-fabricated building decoration process goes as following: integrated building designintegrated design of decoration components of external walls, interior walls and floors - production of integrated components (integrated decoration of production process, design of circuits and water pipelines) - component assembly on site -integrated kitchen and toilet, integrated storage space.

At the same time, in addition to above construction processes, in order to better match pre-fabricated buildings, corresponding decoration process is quite different from the traditional decoration one in design, structure and many other aspects. Specific differences are reflected in following aspects.

The intervention time of pre-fabricated building decoration is different from the intervention time of traditional decoration. Traditional decoration process is completed long after the construction of main structure; house owners need to determine the decoration time and supervise the construction process by their own. The assembled decoration of pre-fabricated buildings requires all 
construction-related professionals to participate in the whole processes of architectural design, as well as component production, transportation and assembly. The decoration process needs to be carried out simultaneously with the construction of main structure.

The construction forms and methods are different. Traditional decoration process is carried out by decoration practitioners independently. Most decoration components are made and installed by technicians on-site; wet construction method is commonly used. The components of integration decoration are made in factories, and assembled on site at the same time with the construction of civil structure. Decoration, civil engineering, installation and other projects share common modules and are carried out synchronously. Decoration workers do not need to independently make components on-site; wet construction method is avoided. For decorative modules which cannot be produced in integration, factories must find an effective way to carry out the part-based production; independent fabricated installation should be carried out afterwards.

Design requirements are different. Traditional decorative designers need to consider design principles and owners' requirements, and provide personalized, order-based design services. Pre-fabricated buildings need standardized design and the integration of architectural and decoration design. According to the principle of industrialized mass production and the preference of a certain group of clients, designers need to put more efforts in balancing designing plan and construction technology, and balancing public appreciation and individuals' aesthetic demands.

The requirements on designers' knowledge structures are different. Compared with traditional decoration designers who only need to grasp general decoration knowledge, decoration designers of pre-fabricated buildings should also learn knowledge about integration process, BIM model collaborative design, professional collision inspection and comprehensive optimization; they also need to understand module information management and related professional knowledge like architecture, structure, electricity and safety. At the same time, high aesthetic and research abilities are also required.

The requirements for skilled workers are different. Traditional decoration project requires construction personnel to have higher levels of construction skills in some single types of work. Thus, traditional decoration construction is usually completed by different groups of skilled workers. The assembled decoration integrates decorative components and materials into structural components. Through industrial production in factories, on-site production links are avoided. Factory industrial workers and on-site assembly workers with a variety of professional knowledge are required.

Management modes are different. Traditional decoration management is the organization and management of technical workers and on-site technical guidance. Assembled decoration management is the standardized management of assembly workers' operation. The process is combined with data measurement, PC component production, construction schedule and distribution plan.

Therefore, the traditional decoration pattern cannot be fully integrated into pre-fabricated buildings because of differences in design thinking, construction methods and technological processes.

\section{The Relationship between Pre-fabricated Buildings and Integrated Decoration}

In recent years, a new type of assembled decoration, the so-called integrated decoration appeared in China. In integrated decoration, materials and components are designed and produced in standardization, and then assembled with the main building structure on the construction site. Currently, assembled decoration is not integrated with main building components; it only focuses on innovations in decoration structure and construction technology. Integrated decoration targets at all kinds of building structures. The ultimate goals of pre-fabricated buildings are integrated and synchronized design, production and construction of main building components and decoration projects. Decorative components should be integrated into main building components as standard components. Therefore, current research and promotion of integrated decoration, to a certain extent, is far from the requirements of pre-fabricated buildings on integrated decoration. 


\section{The Significance of Analyzing the Differences between Traditional Decoration and Pre-fabricated Building Decoration}

Pre-fabricated building requires integrated and simultaneous assembly of decoration components, engineering materials and building components. Integrated decoration is quite different from traditional decoration in aspects of decoration concepts, decoration structures, decoration procedures and decoration technologies. At present, the decoration industry still adopts traditional decoration procedures and construction techniques from personnel training to decoration design and implementation, resulting in the disconnection of decoration components and building components, and gaps between building construction and decoration. These problems seriously hinder pre-fabricated buildings to improve their integration degrees. Strengthening research on the differences between integrated decoration and traditional decoration is of great practical significance in promoting the comprehensive and rapid development of pre-fabricated building industry.

The research can find out differences between the integrated decoration of pre-fabricated buildings and traditional decoration, clarify the specific requirements of pre-fabricated buildings on decoration, promote the transformation and upgrading of decoration industry, and provide technical support for the integrated design, production and assembly of prefabricated components and decorative structural layers of pre-fabricated buildings. Thus, the research can help to reduce technical constraints in pre-fabricated building decoration, and speed up the development of pre-fabricated building industry.

In accordance with the characteristics of pre-fabricated architecture and integrated architectural decoration, talent training units like colleges and universities can reorient the training objectives and training modes of decoration specialty in the context of assembly architecture, so as to provide theoretical basis for talent training in the future.

The research can clarify the demands for pre-fabricated building decoration professionals, so as to promote the construction of suitable curriculum systems and practical training programs in colleges and universities, and to compile school-based teaching materials which can meet professional requirements and realize curriculum objectives. Teachers and experts can then compile personnel training plans which conform not only to the requirements of vocational education reform and development, but also to the actual needs of the market, enterprises and the industry. Qualified integrated decoration personnel need to have a good command of knowledge on decoration and structure, on design and construction, and have independent design thinking as well as teamwork spirit.

To sum up, the traditional decoration specialty cannot meet the development requirements of pre-fabricated building decoration in many aspects. In the final analysis, the demand for decoration technology is the demand for talents. Strengthening the research on differences between traditional decoration and the decoration of pre-fabricated buildings is beneficial to the integration of civil construction and decoration, to the formulation of effective curriculum systems and personnel training programs, and to the sustainable development of architecture construction and architectural decoration. In the future, integrated buildings will become the mainstream of architecture; strengthening the importance of integrated architecture is practical and forward looking, and benefits to the long-term development of this specialty.

\section{Acknowledgement}

Fund Project: This paper is the outcome of the research, Research on Curriculum Reform of Pre-fabricated Building Decoration, which is supported by the Foundation for Key Research Projects on Higher Education Reform of Chongqing Education Committee; Project Number: 172080.

\section{References}

[1] X.D. Qu, X. Wang, The development prospect of pre-fabricated buildings, J. Shanxi Architecture. 09 (2017).

[2] K. Wei, on the development situation of pre-fabricated buildings, J. Low Carbon World. 26 
(2017).

[3] X.M. Xu, The present situation and future development of pre-fabricated buildings, J. Science and Technology. 36 (2016).

[4] X.Y. Wang, X.L. Ruan, Assembly architecture: breakthrough of construction industry transformation, J. China Construction Metal Structure. 11 (2016).

[5] J.S. Lu, Research on design of assembly decoration in modern residence, J. Urbanism and Architecture. 03(2017). 